\title{
Should There Be a Comprehensive Independent Review of Infant Feeding Policymaking?
}

\author{
Stewart Forsyth \\ School of Medicine, University of Dundee, Dundee, UK
}

The improvements in nutritional care, which have led to increased survival and well-being of many children with chronic disease, have been achieved by effective collaborations between scientists, clinicians, and industry [1]. However, in the critically important area of infant and young child nutrition in the general population, partnership working, especially between the $\mathrm{WHO}$ and the infant food industry, has a history of acrimony and division, and consequently infant feeding issues relating to policy and practice that were prominent 4 decades ago are still current today [2]. There has been an unrelenting series of disputes, predominantly relating to alleged violations of the International Code for Breast Milk Substitutes [3], which have provoked high profile acrimonious exchanges, boycotts, and legal proceedings, and because these issues have been so protracted, it has led to an atmosphere of mistrust that has now become embedded between key agencies.

Placing this stakeholder conflict in the context of disappointing global breastfeeding rates [4], deficiencies in complementary feeding [5], the double burden of childhood malnutrition [6], and poor progress in achieving sustainable developmental goals [7], the strengths and limitations of the current policymaking process need to be assessed, and it is proposed that this is undertaken by an independent review. Key objectives of the review may

karger@karger.com

(C) 2020 S. Karger AG, Basel

www.karger.com/anm

Karger" be to determine how an enabling environment can be achieved across infant feeding partnerships, how the diverse nutritional requirements of infants and young children worldwide can be effectively delivered, and how policies can mitigate against future crises in childhood nutrition. Within this remit, there are several key determinants of the current structure and process that should be examined.

\section{Roles and Responsibilities of WHO, World Health Assembly, and Governments}

The constitution of the WHO states that the role of the WHO is to act as the directing and co-ordinating authority on international health and to assist governments, upon request, in strengthening a range of health services, including maternal and child health [8]. The constitution also states that national governments have responsibility for the health of their citizens, and this can only be fulfilled by the provision of adequate health and social measures. For the global and national approach to be effective, there needs to be clarity on their roles and responsibilities within strategic/operational and global/national parameters. In the WHO global infant feeding strategy [9], which was endorsed by the World Health Assembly 
(WHA) in 2002, the recommendations range from general principles on direction and support to specific operational detail, including the number of months every woman worldwide should breastfeed. Similarly, the WHO International Code for Breast Milk Substitutes (the Code) is a highly operational document, providing detailed instruction to industry, health professionals, health systems, and the general public, but there are no similar recommendations for WHO, WHA, and breastfeeding advocacy and activist groups [3].

The WHO infant feeding strategy states that each partner should acknowledge and embrace its responsibilities for improving the feeding of infants and young children and that all partners should work together to achieve fully the strategy's aim and objectives [9]. However, in a recently published comprehensive, independent assessment of the Code, it is stated that "the entire space surrounding the Code remains entrenched with hostility between industry and NGO institutions, many of whom are barely on open speaking terms with one another" [10].

The Code has not been updated since it was published in 1981, and WHA have chosen to publish ad hoc resolutions following WHA meetings. These "subsequent resolutions" are embedded in the WHO/WHA literature, and with the brevity of the resolution documents, policy statements may only be recorded within the WHO secretariat working documents [11]. This process lacks transparency and as a minimum, it has been suggested that $\mathrm{WHO} /$ WHA should take steps to present the Code and subsequent resolutions as a coherent set of standards [10].

Transformational change should ensure that the roles and responsibilities of $\mathrm{WHO}, \mathrm{WHA}$, and governments are distinct and complementary, and global and national recommendations are optimally balanced to ensure that parents receive recommendations that are most pertinent to their child. With a global background of extensive diversity, some WHO recommendations, including the most recent statement that all milk products marketed for children up to the age of 3 years should be considered as breast milk substitutes [12], not only lack scientific and clinical evidence but may also negatively impact on parents because of their lack of sensitivity and plausibility. As a consequence, parental non-compliance remains high with many parents choosing to develop a personal infant feeding plan that they believe will best serve their infant's needs. To address this issue, governments should be encouraged to embrace the underlying principles of the WHO and WHA but also provide national recommendations on infant feeding that more closely reflect national needs and are supported by national stakeholders.

\section{Roles and Responsibilities of Policymakers, Health Professionals, and Industry}

In response to unethical marketing and promotion of infant formulas by industry during the 1960s and 1970s, the WHA endorsed the International Code in 1981 [3]; however, because of continuing violations, the WHA continues to issue resolutions that add further restriction on the activities of industry. In addition, many of the breastfeeding advocacy and activist groups have continued to support protests, boycotts, and legal actions against infant formula companies, especially Nestlé [2]. However, despite 4 decades of anti-industry activity, non-compliance with WHO infant feeding recommendations persists, Nestlé is now the largest food and beverage company in the world [13], formula sales are rising [14], and nutrition-related factors contribute to $45 \%$ of deaths in children under 5 years of age [15].

It is unworthy of leading health and nutrition institutions to adopt positions of non-cooperation when they should be collectively focussing on the development of child feeding policies that reflect the diverse nutritional and socio-economic circumstances. Moreover, collateral damage is impacting on all stakeholders, including scientists [16-18], health practitioners [19, 20], and families [21]. Understanding the interface between policymakers, health professionals, and industry is critically important if multi-professional delivery of effective infant feeding policy is going to be successful [22]. Policymakers have responsibility for the development of policy for populations that may be national or global, and the one-sizefits-all global infant feeding policies recommended by WHO contrast with the healthcare approach that is focused on providing care for individual children and their families. Clinical practice is not an exact science [23], and good judgement is extremely important in managing infant feeding issues as there are many nutritional and non-nutritional confounding factors that need to be taken into consideration. With these different approaches, it is not surprising that health practitioners may find themselves making some clinical decisions that they believe are in the best interests of the child, but may not be compliant with global policies, including the International Code.

Similarly, if health professionals are to provide the best nutritional care for children under their care, there will be circumstances when good practice will be to consult with industry, and this may lead to collaborative research [24]. It is, therefore, important that there is an enabling environment across infant feeding partnerships that will 
ensure that the best nutrition can be developed and delivered to all infants and young children, and especially those living in the most difficult circumstances.

\section{Parent Friendly Policies}

A review of public engagement and policymaking stated that effective policy requires transparency, accessibility, and responsiveness of as wide a range of citizens as possible [25]. To be successful, these elements must be applied at all stages of the design and delivery of public services, as this will provide a better understanding of the evolving and diverse needs within populations. Moreover, it is important to reach out beyond the "usual suspects" and avoid the risk of policy being hijacked by the vociferous few who are unlikely to be representative of the silent majority. Compliance with infant feeding policy requires consensus from parents, and consensus from parents requires consultation with parents. Moreover, the needs of a population will evolve, and policies need to adapt to societal change, for example, the rapid expansion of the female workforce $[26,27]$ and laws on freedom of information which underline the importance of information access, not only as a human right but also as a right to ensure good governance [28].

The Code states that parents can only receive scientific and factual information from healthcare workers [3]. However, today the public expect to have immediate access to electronically delivered information, and they are now accustomed to the process of accessing search engines, assimilating information, and making choices. It is extremely important that communication with parents is mature and transparent, and a balanced view is taken on the prevention of inappropriate marketing and promotion of both breastfeeding and infant formulas.

Breastfeeding is a single entity that must be considered within the context of other nutritive and non-nutritive factors that impact on the health and well-being of infants and children. Open and inclusive multi-factorial policymaking that pulls together these interdependent factors may be more receptive to families and their healthcare professionals, and this holistic approach may, therefore, be more effective at a national rather than a global level. With due diligence to global principles, individual regions and countries should assess their own level of nutritional risk and shape infant feeding policies to meet the broader health and social needs of families at risk. The review panel needs to consider if there should be a minimum standard for infant feeding practice that can be ad-

Independent Review of Infant Feeding Policymaking justed according to specific national risk factors. This potential stepwise approach to infant feeding decision-making may be viewed as more realistic to parents who are sceptical of being given the same advice if they live in Switzerland or Sierra Leone [21].

\section{Integrated Approach to the Infant and Young Child Diet}

Although policies and directives should be cognizant of the nutritional interdependence between breast milk and complementary foods [29], research and policy tend to consider these nutritional sources as separate entities, with breastfeeding overshadowing the importance of complementary foods. The Lancet Breastfeeding Series in 2016 published an article by Victora and colleagues [30] who reported that scaling-up breastfeeding to universally recommended targets will prevent 823,000 deaths worldwide, and this statement now frequently headlines infant feeding policy documents. The analysis of this study focused on 75 countries with the highest child mortality rates worldwide, and data on complementary feeding were not included. Paradoxically, countries with the longest breastfeeding duration generally have the highest childhood mortality and stunting [31], and from a nutrition perspective, this can be explained by reverse causality, with the longer duration of breastfeeding reflecting the lack of good-quality complementary foods in the study populations, and in these circumstances breast milk acts as an inadequate complementary food substitute. Although breast milk may be providing sufficient energy and nutrients for survival in early life, the failure to simultaneously scale-up complementary feeding will inevitably lead to later child mortality and morbidity.

The WHO strategy for infant and young child feeding states that complementary foods should be nutrient-rich, home-prepared, locally available products, including animal source food [9]; however, this is not possible for populations where complementary foods are not readily available and preparation is hazardous because of unclean water and lack of sanitation facilities. In those circumstances, stakeholders, including industry, need to work together to ensure that supply chains of potential life-saving food products are made available. It is noted that in 9 WHA resolutions relating to infant feeding from 2005 to 2018 , breastfeeding was mentioned 41 times and the words complementary feeding 7 times (unpublished data), and it has been postulated that breaches of the Code have fuelled policymakers' suspicions that industry will 
exploit opportunities to promote complementary food products and potentially breach policy recommendations [32]. Industry, in turn, has become wary of breastfeeding advocates and activists, viewing them as potentially hostile to their brand name and consequently, there has been a reluctance to play a meaningful role in scaling-up complementary products. In the meantime, industry has seen the opportunity to focus on the older child with fast foods, confectionary, and sugary drinks which have contributed to the obesity component of the double burden of malnutrition [33]. Although the Code was developed to limit the actions and behaviours of industry [3], it also limits the opportunities for other members of the infant feeding community to work with the food industry to improve the quality of complementary feeding and to provide a foundation for a diverse balanced diet in later childhood.

In the recent Lancet Series on the double burden of malnutrition, it is suggested that actions to address undernutrition and overweight and obesity have historically adopted a policy silo approach, and there is emerging evidence that programmes addressing undernutrition have unintentionally increased risks for obesity and dietrelated non-communicable diseases in low- and middleincome countries [34]. A more holistic approach is now proposed, and this development reinforces the need for a fully integrated approach to all aspects of infant and young child feeding, that provides an optimum balance between breast and complementary feeding, which reflects socio-economic and cultural diversity and is compatible with eco-friendly sustainability.

\section{Independent Regulatory Authorities}

There needs to be clarity on who or what is being regulated and by whom. Boundaries for the regulation of marketing and promotion of breast milk substitutes are becoming increasingly blurred with scientists, health professionals and parents becoming caught up in the efforts of WHO to restrict this practice [16-21]. Clear lines of responsibility are required for the marketing and promotion by industry, and this should be assessed by an independent regulatory body. Scientists and healthcare professionals are already under the jurisdiction of statutory regulatory systems and concerns regarding practice or behaviour should be channelled through these authorities. Families should not only be able to contribute to the development of policy proposals but they also should be protected from proposals that may be perceived as insensitive to their needs, and therefore a citizen's communication system, provided by an independent body, could provide valuable consumer data that can inform policy development.

Even with the best partnership working, claims of conflict of interest will inevitably emerge and the material risk identified in the claim needs to be assessed with due diligence to ensure that the evaluation does not fall victim to further conflicts of interest [24]. A blatant conflict of interest should be easily identified; however, assessment of a potential conflict of interest introduces elements of judgement and opinion rather than fact, and in those circumstances, there may be a fine divide between good judgement, self-interest and conflict of interest. With this potential level of uncertainty, it is essential that claims of conflict of interests are responsible and proportionate, and they are not used as a tool by individuals or organizations to advance self-interest and create further division and distrust.

From a regulatory perspective, the WHO co-ordinates a monitoring system called NetCode in partnership with UN system organizations, WHO Collaborating Centres, NGOs who are particularly active in supporting breastfeeding, and selected Member States [35]. Their key objective is to monitor compliance with the Code and to "hold manufacturers, distributors, retail outlets, the healthcare system and healthcare workers to account for their breaches of national laws and/or the Code." However, the organizations who initiated this process and also participate as monitors, have a long history of preventing industry involvement in all aspects of infant feeding policy and practice, and therefore, they themselves have a material conflict of interest. The structure of NetCode is clearly divisive with one half of the infant feeding community monitoring the other half, and it is noted that there is not a reciprocal arrangement. Furthermore, it could be argued that the least regulated organizations are regulating the most regulated organizations.

The foundations of good practice are dependent upon all organizations involved in the infant feeding community being able to demonstrate optimum standards for professionalism, governance, and regulation, and these should be assessed by independent regulatory bodies. Organizations who are considered by their regulatory body not to meet these standards should not participate in infant feeding policymaking.

\section{The Way Forward}

The interdependent roles of breast milk, complementary foods, and infant formulas if required, should be central to academic research and multi-stakeholder policy- 
making, and without prejudice, the focus should be on delivering an integrated, balanced nutritional diet for infants and young children that is specific for their age and socio-economic circumstances. For this to be achieved, changes in the current approach are required, and this article has identified several key determinants that can be considered in an independent review that is long overdue.

As a precedent, it is noted that in 2015, the WHA members requested that the WHO Director-General establish a Review Committee to examine the role of the international health regulations in the Ebola outbreak in 2014 and to consider the WHO response [36, 37]. There were 28,616 cases and 11,310 deaths from Ebola infection in Guinea, Liberia, and Sierra Leone. In 2018, there were 2.4 million nutrition-related childhood deaths worldwide [15], and with a background of partnership dysfunction and failure to meet key objectives, WHA members should be seeking assurance on performance and governance, and an independent review that would critically consider the strengths and limitations of the current infant feeding policymaking process would be a responsible way for- ward. Anticipated outcomes of the review would be the establishment of an enabling environment across infant feeding partnerships, an integrated approach to the delivery of diverse nutritional diets for infants and young children worldwide, and development of new strategies to mitigate against future crises in childhood nutrition. Early life nutrition is the foundation of future health and current evidence indicates that this jewel of human life deserves better.

\section{Disclosure Statement}

I have received research grants from the government, charitable organizations, and industry; and consultancy fees and honoraria from government and industry, including companies that produce infant formula. I currently receive consultancy fees from DSM Nutritional Products, an international ingredient supplier.

\section{Funding Sources}

There is no funding related to this manuscript.

\section{References}

1 Larson-Nath C, Goday P. Malnutrition in children with chronic disease. Nutr Clin Pract. 2019;34:349-58.

2 Forsyth JS. International code of marketing of breast-milk substitutes: three decades later time for hostilities to be replaced by effective national and international governance. Arch Dis Child. 2010;95(10):769-70.

3 World Health Organisation. International Code of Marketing of Breast-milk Substitutes. 1981. Available from: https://www.who.int/ nutrition/publications/code_english.pdf.

4 World Health Organisation. UNICEF. Enabling women to breastfeed through better policies and programmes: global breastfeeding scorecard. 2018. Available from: https://www. who.int/nutrition/publications/infantfeeding/ global-bf-scorecard-2018.pdf?ua=1.

5 White JM, Bégin F, Kumapley R, Murray C, Krasevec J. Complementary feeding practices: current global and regional estimates. Matern Child Nutr. 2017;13(Suppl 2):e12505. https://onlinelibrary.wiley.com/doi/ epdf/10.1111/mcn.12505. http://dx.doi.org/ 10.1111/mcn.12505

6 Popkin BM, Corvalan C, Grummer-Strawn LM. Dynamics of the double burden of malnutrition and the changing nutrition reality. Lancet. 2020;395(10217):65-74.

7 United Nations. The sustainable development goals report. 2019. Available from: https://unstats.un.org/sdgs/report/2019/ The-Sustainable-Development-Goals-Report-2019.pdf.
8 Constitution of the World Health Organisation (2006). Basic Documents, Forty-fifth edition, Supplement. Available from: http:// www.who.int/governance/eb/who_constitution_en.pdf.

9 World Health Organisation and UNICEF. Global strategy for infant and young child feeding. 2003. Available from: https://apps. who.int/iris/bitstream/handle/10665/42590/ 9241562218.pdf; jsessionid=399EBD25229B3 6F58C79B6521F2E399C? sequence $=1$.

10 Evans A (2018) Food for Thought. An independent assessment of the International Code of Marketing of Breast-milk Substitutes. Breastfeeding Innovation Team. Available from: https://www.dropbox.com/s/ 8 acidrqbt 2 rlm $7 \mathrm{u} /$ FoodforThoughtReport_ print\%28hi-res\%29.pdf?dl=0.

11 Grummer-Strawn LM. Confusion over breast milk substitutes. J Pediatr Gastroenterol Nutr. 2019;68(2):e41-2.

12 Forsyth S. Is the WHO creating unnecessary confusion over breast milk substitutes? J Pediatr Gastroenterol Nutr. 2018;67(6):760-2.

13 Forbes Global. The world's largest food and restaurant companies. 2019. Available from: https: //www.forbes.com/sites/chloesorvino/ 2019/05/15/worlds-largest-food-restaurantcompanies-2019/\#5a2794e5fod 1 .

14 Rollins NC, Bhandari N, Hajeebhoy N, Horton S, Lutter CK, Martines JC, et al. Why invest, and what it will take to improve breastfeeding practices? Lancet. 2016;387(10017): 491-504.
15 World Health Organisation. Children: reducing mortality. 2019. Available from: https:// www.who.int/news-room/fact-sheets/detail/ children-reducing-mortality.

16 Godlee F. Disentangling ourselves from "big formula”. BMJ. 2018;363:k5146.

17 van Tulleken C. Overdiagnosis and industry influence: how cow's milk protein allergy is extending the reach of infant formula manufacturers. BMJ. 2018;363:k5056.

18 Forsyth S. Formula milk studies couldn't exist without industry. BMJ. 2019;364:1367.

19 Costello A, Branca F, Rollins N, Stahlhofer M, Grummer-Strawn L. Health professional associations and industry funding. Lancet. 2017;389(10069):597-8.

20 Grummer-Strawn LM, Holliday F, Jungo KT, Rollins N. Sponsorship of national and regional professional paediatrics associations by companies that make breast-milk substitutes: evidence from a review of official websites. BMJ Open. 2019;9(8):e029035.

21 Hoddinott P, Craig LCA, Britten J, Rhona MM. A serial qualitative interview study of infant feeding experiences: idealism meets realism. BMJ open. 2012;2(2):e000504.

22 Forsyth S. Should the world health organization relax its policy of non-cooperation with the infant food industry? Ann Nutr Metab. 2018;73(2):160-2.

23 Panda SC. Medicine: science or art? Mens Sana Monogr. 2006;4(1):127-38. 
24 Forsyth S. Infant feeding and conflict of interest: a healthcare perspective. Ann Nutr Metab. 2019;75(4):252-255.

25 Organization for Economic Cooperation and Development (2009) Focus on Citizens: Public Engagement for Better Policy and Services. Available from: http://www.oecd.org/governance/regulatory-policy/focusoncitizenspublicengagementforbetterpolicyandservices.htm.

26 Toossi M, Morisi TL. Women in the workforce before, during, and after the great recession. 2017. Available from: https://www.bls. gov/spotlight/2017/women-in-the-workforce-before-during-and-after-the-great-recession/pdf/women-in-the-workforce-before-during-and-after-the-great-recession. pdf.

27 Ortiz-Ospina E, Tzvetkova S. Working women: Key facts and trends in female labor force participation. Our World in Data. Available from: https://ourworldindata.org/female-labor-force-participation-key-facts.
28 Naib S. Freedom of information: a global perspective. 2019. Available from: https://www. oxfordscholarship.com/view/10.1093/acprof: oso/9780198067474.001.0001/acprof9780198067474-chapter-1.

29 World Health Organisation. Complementary feeding of young children in developing countries: a review of current scientific knowledge. Geneva; 1998. Available from: file: ///C: /Users/user/Downloads/WHO NUT_98.1.pdf.

30 Victora CG, Bahl R, Barros AJD, França GVA, Horton S, Krasevec J, et al. Breastfeeding in the 21st century: epidemiology, mechanisms, and lifelong effect. Lancet. 2016;387(10017): 475-90.

31 Forsyth S, Gautier S, Salem N Jr. Dietary intakes of arachidonic acid and docosahexaenoic acid in early life: with a special focus on complementary feeding in developing countries. Ann Nutr Metab. 2017;70(3):217-27.

32 Singh JA, Daar AS, Singer PA. Shared principles of ethics for infant and young child nutrition in the developing world. BMC Public Health. 2010;10:321. http://www.biomedcentral.com/1471-2458/10/321 http://dx.doi.org/ $10.1186 / 1471-2458-10-321$
33 Drewnowski A. The economics of food choice behavior: why poverty and obesity are linked. In: Drewnowski A, Rolls B, editors. Obesity treatment and prevention: new directions. Nestlé Nutrition Institute Workshop Series. Basil: Nestec Ltd, Vevey/S Karger AG; 2012. Vol. 73; p. 95-112.

34 Branca F, Demaio A, Udomkesmalee E, Baker $\mathrm{P}$, Aguayo VM, Barquera S, et al. A new nutrition manifesto for a new nutrition reality. Lancet. 2020;395(10217):8-10.

35 World Health Organization, United Nations Children's Fund. NetCode toolkit. Monitoring the marketing of breast-milk substitutes: protocol for ongoing monitoring systems. Geneva: World Health Organization; 2017. Licence: CC BY-NC-SA 3.0 IGO.

36 World Health Organisation. Ebola outbreak. 2014-2016. Available from: https://www. who.int/csr/disease/ebola/en/.

37 World Health Organisation. An R\&D blueprint for action to prevent epidemics. Plan of action. 2016 May. Available from: https:// www.who.int/blueprint/about/r_d_blueprint_plan_of_action.pdf?ua $=1$. 